\title{
Effects of incident wind/wave directions on dynamic response of a SPAR-type floating offshore wind turbine system
}

\author{
Guoqin Lyu ${ }^{1,2} \cdot$ Huiqin Zhang ${ }^{1,2}$. Jiachun $\mathrm{Li}^{1,2}$
}

Received: 31 January 2019 / Revised: 6 May 2019 / Accepted: 20 May 2019 / Published online: 25 June 2019

(c) The Author(s) 2019

\begin{abstract}
As a promising renewable energy, offshore wind energy currently is gaining more attention, by which the economic and efficient operation of floating wind turbine systems is a potential research direction. This study is primarily devoted to the analysis of dynamic response of the NREL-5 MW reference wind turbine supported by an OC3-Hywind SPAR-type platform using a recompiled code which combines FAST with WAMIT. To verify the reliability of the recompiled code, the free decay motions of a floating wind turbine system in still water are examined with satisfactory results. After that, thirteen scenarios with different angles between wind and wave from $0^{\circ}$ to $90^{\circ}$ are investigated. The dynamic responses of the turbine system in various degrees of freedom (DOFs) for different incident wind/wave directions are presented in both time and frequency domains via the fast Fourier transform.
\end{abstract}

Keywords Offshore floating wind turbine $\cdot$ Dynamic responses $\cdot$ SPAR-type wind turbine . Distributions of wind and wave directions

\section{Introduction}

As a kind of clean and renewable energy, wind energy has become an important part of green energy and exhibited great potential owing to its abundant reserves, broader territory, and stable and sustained operation [1]. In addition, offshore wind turbines display less visual and noise pollution when compared with onshore wind turbines. In recent years, the global installed capacity of offshore wind power has increased rapidly. The cumulative installed capacity in the world reached $18.8 \mathrm{GW}$ by the end of 2017 , of which the installed capacity from 2011 to 2017 was as high as 15.7 GW [2]. It is very promising that exploitation of offshore wind energy could become a new pathway to acquire clean energy.

\footnotetext{
Huiqin Zhang

zhanghuiqin@imech.ac.cn

$凶$ Jiachun Li

jcli05@imech.ac.cn

1 Key Laboratory for Mechanics in Fluid Solid Coupling System, Institute of Mechanics, Chinese Academy of Sciences, Beijing 100190, China

2 School of Engineering Science, University of Chinese Academy of Sciences, Beijing 100049, China
}

With the increase of water depth, the cost of traditional foundations for fixed platforms rises dramatically [3]. Therefore, the concept of offshore floating wind turbines was proposed. The offshore wind turbine system generally consists of four parts: wind turbine, tower, floating support platform and mooring system. The aerodynamic responses of a wind turbine and tower can interact with the hydrodynamic responses of a floating support platform and mooring system. Optimization of the dynamic response of an offshore wind turbine system subjected to wind and waves considering the aerodynamic-hydrodynamic coupling effect is one of the major concerns for improving the safety margin of wind turbine systems [4, 5].

A fully coupled simulation tool was developed by Jonkman [6] for hydrodynamic-aerodynamic-controlstructural response, which mainly integrates together the main functions of FAST, AeroDyn and HydroDyn. Based on that, they calculated the overall loads of a barge-type floating wind turbine system; the coupling effects between the wind turbine and floating foundation and the dynamic response of the system are presented and discussed. The NREL-5MW offshore wind turbine was simulated by Tran et al. [7, 8] by using star-CCM+ and overlapping grid technique. The periodic motion of the given wind turbine is shown with the platform simultaneously presented by the non-FAST tool. 
When compared with unsteady blade element momentum theory (UBEM), it is found that the instantaneous aerodynamic loads by UBEM are higher than those calculated by computational fluid dynamics (CFD) approaches. Using the actuator disk model, de Vaal et al. [9] examined the effect of surge motion on the aerodynamic load and inducing factor of the turbine. At the same time, they also used the blade element momentum theory and two widely used dynamic inflow models to verify the same example. It is found that whether the dynamic inflow models is considered or not has insignificant impact on the surge motion. Investigation was conducted by Nielsen et al. [10] of the dynamic response of a Hywind floating system at a model scale considering the coupling effects, and the corresponding results are validated with the experimental results. Furthermore, Yu et al. [11] calculate a SPAR-type floating wind turbine, and they reported that when the floating wind turbine is subjected to the combined action of incident wind and waves, the wind load mainly determines the distance from the initial position to the quasi-equilibrium position, and the wave load mainly excites oscillation of the wind turbine around the quasi-equilibrium position.

In the aforementioned studies, the incident wind perpendicular to the blade disk of the wind turbine is usually assumed to have the same direction as the waves. However, this assumption is not always valid in real sea. For example, the swells from afar could have different direction than the local wind and waves. Sometimes, the sudden change of the wind direction could also result in an angle between the wind and waves [12]. In these circumstances, the aerodynamic-hydrodynamic coupling effect could differ from the situation when the wind and waves have the same direction. The European code for offshore wind turbine, IEC61400-3, emphasizes that the calculation of those cases with different incident wind/wave directions should be considered in the design process in the future [13].

Since the effects of incident wind/wave directions on the dynamic response of floating wind turbine systems are scarcely discussed at present, the investigation of dynamic response of a SPAR-type wind turbine system under the coupled action of wind and waves has motivated this study. Particular attention is paid to the influence of incident wind/wave directions on the six degrees of freedom (DOFs) which is discussed in both time and frequency domains.

\section{Model description}

The offshore wind turbine system is based on the OC3Hywind floating wind turbine concept. The integrated system can be divided into three main components: wind turbine, floating foundation and mooring system. Figure 1 illustrates the OC3-Hywind turbine system.

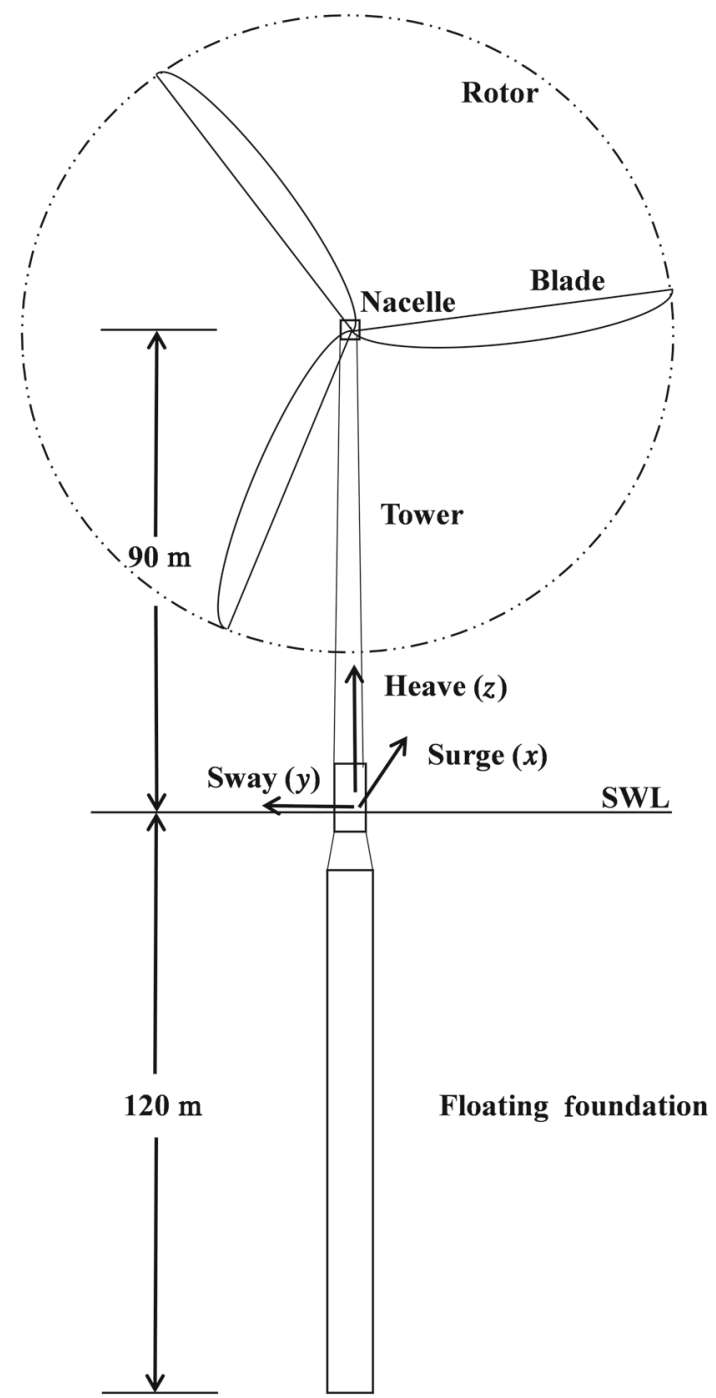

Fig. 1 Sketch of the OC3-Hywind system (SWL: still water line)

\subsection{Governing equations of a wind turbine system}

When the offshore wind turbine system is subjected to the wind and wave loads, the system will experience the six DOF motions as illustrated in Fig. 2, i.e., surge, sway, heave, pitch, roll and yaw. The whole system of the floating turbine is regarded as a floating rigid body with constraints and external loads, which is governed by Eq. (1)

$\boldsymbol{M} \ddot{x}(t)+\boldsymbol{B} \dot{x}(t)+\boldsymbol{K} x(t)=\boldsymbol{F}$,

where matrix $\boldsymbol{M}$ represents the inertia (rotational inertia) of the floating body, and the matrix $\boldsymbol{B}$ denotes viscous damping and radiation damping, while the matrix $\boldsymbol{K}$ is called stiffness matrix due to restored force from buoyancy and the linearized restoring from the mooring line. The mass matrix $\boldsymbol{M}$ includes the mass matrix of structure $\boldsymbol{M}_{0}$ and the added 


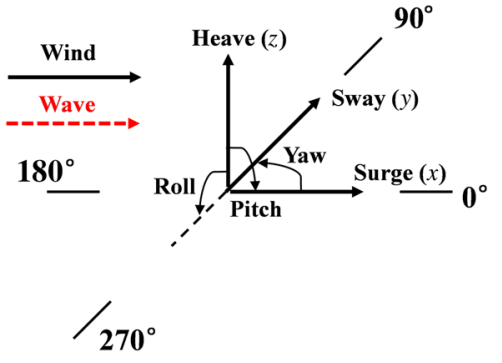

Fig. 2 Six DOFs motions and the global coordinate of the system

(or virtual) mass matrix $\boldsymbol{M}_{\mathrm{a}}$. Due to the radiation damping induced by the movement of the floating foundation nearby the free surface of water, the damping matrix $\boldsymbol{B}$ satisfies $\boldsymbol{L}(t)=\frac{2}{\pi} \int_{0}^{\infty} \boldsymbol{B}(\omega) \cos (\omega t) \mathrm{d} \omega$, where $\boldsymbol{L}$ is called the retardation function and $\omega$ is the frequency [14]. The external force contains the forces due to aerodynamic load $\boldsymbol{F}_{\text {wind }}$, hydrodynamic load $\boldsymbol{F}_{\text {hydro }}$, and that by the mooring system $\boldsymbol{F}_{\text {mooring }}$.

Consequently, the offshore floating body is governed by

$$
\begin{gathered}
\left(\boldsymbol{M}_{0}+\boldsymbol{M}_{\mathrm{a}}\right) \ddot{x}(t)+\int_{0}^{t} \boldsymbol{L}(t-\tau) \dot{x}(t) \mathrm{d} \tau+\boldsymbol{K} x(t) \\
=\boldsymbol{F}_{\text {wind }}+\boldsymbol{F}_{\text {hydro }}+\boldsymbol{F}_{\text {mooring }},
\end{gathered}
$$

where $\boldsymbol{F}_{\text {wind }}$ is calculated by the aerodynamic module in FAST based on the blade element momentum (BEM) theory, and $\boldsymbol{F}_{\text {mooring }}$ is calculated by the mooring module based on quasi-static method. Since the hydrodynamic module, HydroDyn, in the current FAST code which uses the linear theory of wave diffraction is unable to calculate the high-order wave force [15], the hydrodynamic parameters (damping coefficient, added mass coefficient, first-order and second-order wave transfer function) of the floating support platform are derived by WAMIT, and the relevant results are transmitted to FAST. Based on the recompiled code integrating FAST with WAMIT, the dynamic responses can be obtained by solving Eq. (2).

\subsection{Wind turbine floating foundation and mooring system}

The wind turbine model is NREL's 5-MW baseline wind turbine, which has been widely used as a reference model to standardize and quantify wind energy technology. NREL's 5-MW baseline wind turbine is a conventional, three-bladed, upwind wind turbine. Its control systems are composed of a collective blade-pitch controller and generator-torque controller. The main parameters are listed in Table 1, and more detailed parameters of the blade and tower can be found in Ref. [16].
Table 1 Parameters of the wind turbine system [16]

\begin{tabular}{ll}
\hline Term & Value \\
\hline Rotor diameter $(\mathrm{m})$ & 126 \\
Hub height $(\mathrm{m})$ & 90 \\
Cut-in, rated, cut-out wind speed $(\mathrm{m} / \mathrm{s})$ & $3,11.4,25$ \\
Rotor mass $(\mathrm{kg})$ & $1.1 \times 10^{5}$ \\
Nacelle mass $(\mathrm{kg})$ & $2.4 \times 10^{5}$ \\
Tower mass $(\mathrm{kg})$ & $3.475 \times 10^{5}$ \\
Coordinate location of overall center of mass $(\mathrm{CM})$ & $(-0.2,0,64)$ \\
$(\mathrm{m})$ & \\
\hline
\end{tabular}

Table 2 Parameters of floating platform [16]

\begin{tabular}{ll}
\hline Term & Value \\
\hline Total draft $(\mathrm{m})$ & 120 \\
Elevation to platform above SWL $(\mathrm{m})$ & 10 \\
Depth to top of taper below SWL $(\mathrm{m})$ & 4 \\
Depth to bottom of taper below SWL (m) & 12 \\
Platform diameter above taper (m) & 6.5 \\
Platform diameter below taper $(\mathrm{m})$ & 9.4 \\
Platform mass (including ballast) $(\mathrm{kg})$ & $7,466,330$ \\
CM location below SWL along platform centerline & 89.92 \\
$\quad(\mathrm{~m})$ & \\
Platform roll inertia about CM $\left(\mathrm{kg} \cdot \mathrm{m}^{2}\right)$ & $4.23 \times 10^{9}$ \\
Platform pitch inertia about CM $\left(\mathrm{kg} \cdot \mathrm{m}^{2}\right)$ & $4.23 \times 10^{9}$ \\
Platform yaw inertia about platform centerline & $1.64 \times 10^{8}$ \\
$\left(\mathrm{~kg} \cdot \mathrm{m}^{2}\right)$ & \\
\hline
\end{tabular}

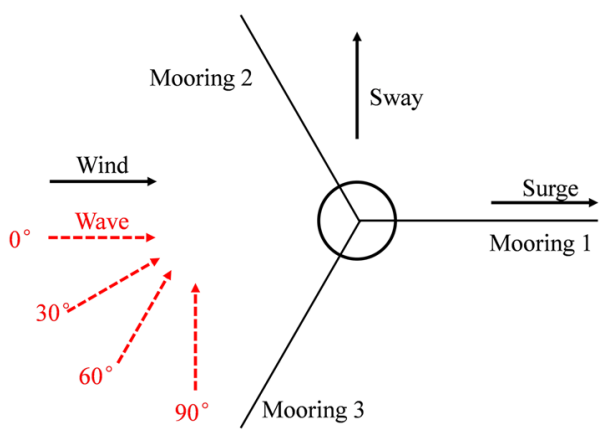

Fig. 3 Sketch of the OC3-Hywind mooring system and environmental parameters setting

The floating foundation bearing the tower is comprised of two coaxial columns of different radii with a transitional taper between them. The diameters of the top thin column and bottom thick column are $6.5 \mathrm{~m}$ and $9.4 \mathrm{~m}$, respectively. The thick cylinder, with the majority of volume, is the core of the buoyancy provider. The main parameters of the floating foundation are listed in Table 2. 
Table 3 Properties of mooring system [16]

\begin{tabular}{ll}
\hline Term & Value \\
\hline Depth to anchors below SWL (m) & 320 \\
Depth to fairleads below SWL (m) & 70 \\
Radius to anchors from platform centerline (m) & 853.87 \\
Radius to fairleads from platform centerline (m) & 5.2 \\
Upstretched mooring line length (m) & 902.2 \\
Mooring line diameter (m) & 0.09 \\
\hline
\end{tabular}

The OC3-Hywind possesses a mooring system composed of three slack catenary lines. Fairleads are connected with the floating foundation, and anchors are fixed on the seabed. Figure 3 shows the distribution of the coordinate system for mooring. The three mooring lines are oriented symmetrically at $0^{\circ}, 120^{\circ}$, and $240^{\circ}$ about the vertical axis. Relevant information for the mooring system is listed in Table 3.

\section{Results and discussions}

\subsection{Model verification}

To validate the recompiled code integrating FAST with WAMIT, the free decay motions are examined firstly. Here,
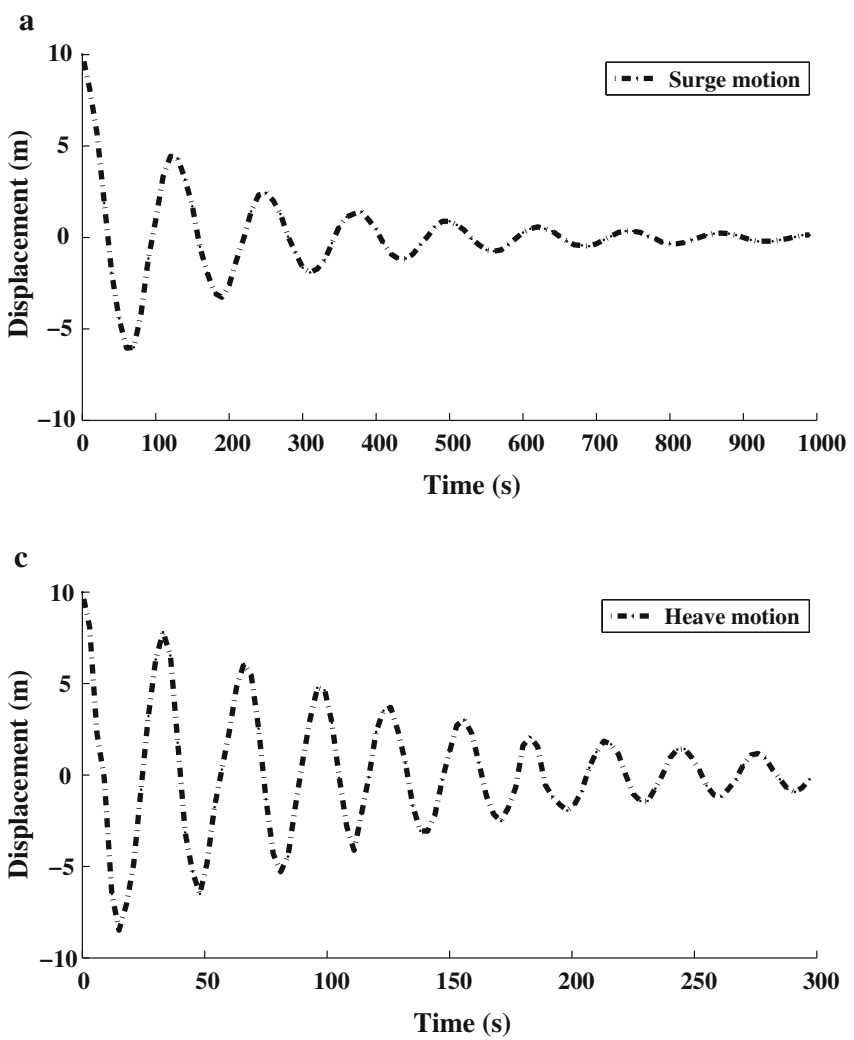

the free decay motion means the dynamic response of the offshore wind turbine system subjected to a non-equilibrium initial condition without any environmental wind/wave loads. According to the geometric model of the reference wind turbine and the arrangement forms of the anchor chains, it can be estimated that the maximum horizontal displacement of the single anchor chain is about $35 \mathrm{~m}$. Therefore, the initial displacements of the three translational directions (surge, sway and heave) are set as $10 \mathrm{~m}$ (less than the limit case), and the initial displacements of the three rotation directions (pitch, roll and yaw) are set as $10^{\circ}$.

Figure 4 shows the hydrostatic decaying processes of the SPAR-type wind turbine in the six DOFs. The calculated natural period of six motion modes of the whole system are listed in Table 4, together with the results provided by Jonkman and Musial [17] for the purpose of comparison.

Since the geometric model of the SPAR-type floating platform is symmetrical about the two horizontal axes, and the upper wind turbine is not operating, there is no aerodynamic load applied on the blade. Therefore, the translational motion of the surge motion is extremely close to the sway motion, and the pitch motion is close to the roll motion as well. The natural frequencies of surge, pitch and heave motion of the reference floating wind turbine are about $0.05,0.21$ and $0.20 \mathrm{rad} / \mathrm{s}$,
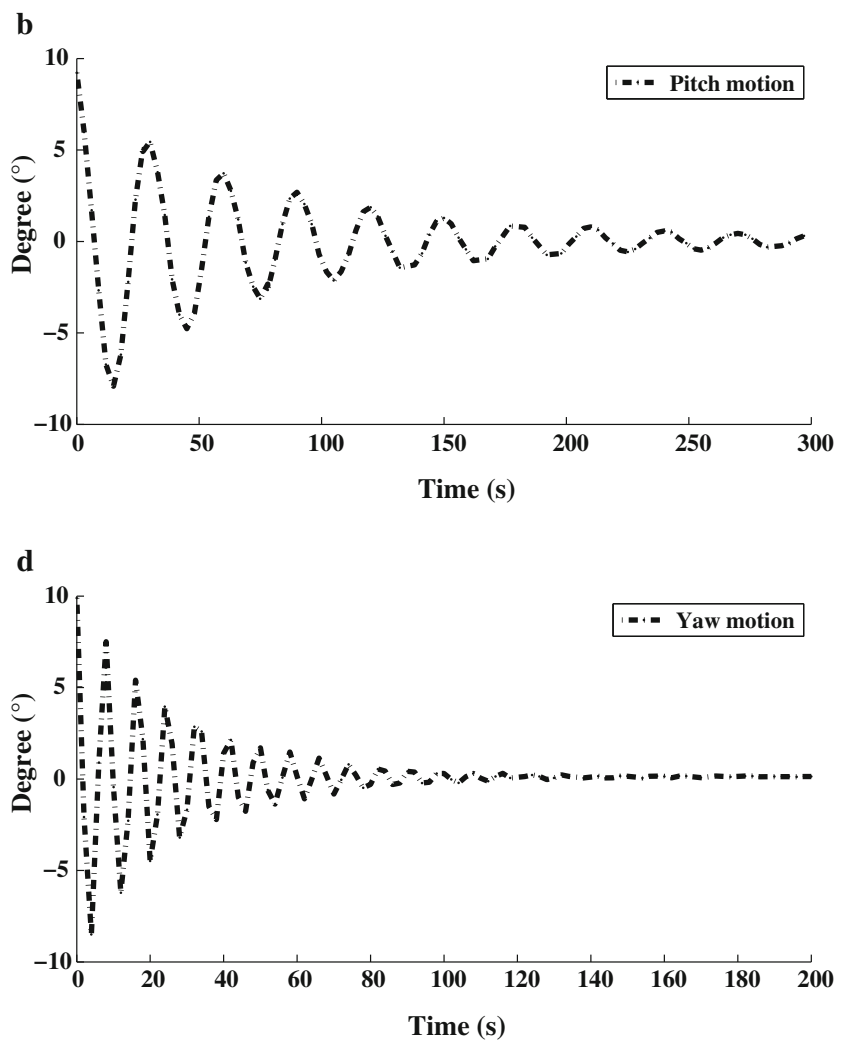

Fig. 4 Free decay in platform motion in the six DOFs. As symmetry of the SPAR-type floating platform, the surge motion is extremely close to the sway motion, and the pitch motion is close to the roll motion. a Surge decay motion, b pitch decay motion, $\mathbf{c}$ heave decay motion, $\mathbf{d}$ yaw decay motion 
Table 4 Natural periods of the reference wind turbine

\begin{tabular}{lcc}
\hline Motion mode & Natural period (s) & Period of Ref. [17] (s) \\
\hline Surge & 125.6 & 125.8 \\
Sway & 124.8 & 124.9 \\
Heave & 30.7 & 30.9 \\
Pitch & 30.0 & 30.0 \\
Roll & 30.0 & 30.0 \\
Yaw & 8.3 & 8.3 \\
\hline
\end{tabular}

respectively. The calculated results are consistent with those in Jonkman and Musial [17].

In fact, we are able theoretically to derive the natural period in heave motion as

$T \sim 2 \pi \sqrt{\frac{L}{g}} \frac{d_{\max }}{d_{\min }}=31.8$,

where $L$ represents the total draft of the floating foundation, and $d_{\max }$ denotes the maximum diameter of the submerged cylinder, while $d_{\text {min }}$ denotes the minimum diameter of the submerged cylinder at the sea surface which is also in agreement with computation.

Based on the natural frequencies of the six DOFs free decay motions, it shows that the recompiled code integrating FAST with WAMIT is reliable. Using the validated code, the dynamic responses of the reference wind turbine in various scenarios of different incident wind and wave directions are ready to be obtained.

\subsection{Effects of wind and wave directions}

Considering the characteristics of the wind turbine, the rotor is assumed to adapt to incident wind direction and ensure that the wind direction is perpendicular to the blade disk of the wind turbine as much as possible to maximize captured atmospheric energy. Therefore, we presumably believe that the direction of incident wind is always blowing in the $x$ direction (surge direction) as shown in Fig. 2. The constant wind speed is set as $11.4 \mathrm{~m} / \mathrm{s}$, which has the most significant influence on the rated wind speed [18]. Meanwhile, JONSWAP spectra are supposed for local stochastic wave conditions written in the following expression [19]

$S(\omega)=A \frac{H_{1 / 3}^{2}}{T_{\mathrm{p}}^{4} \omega^{5}} \exp \left(-\frac{1.25}{T_{\mathrm{p}}^{4} \omega^{4}}\right) \gamma^{\exp \left[\frac{-\left(\omega T_{\mathrm{p}}-1\right)^{2}}{2 \sigma^{2}}\right]}$,

where $T_{\mathrm{p}}$ represents the peak period of the spectrum, and $H_{1 / 3}$ means the significant wave height. $\gamma$ is the spectral peak factor of 3.3 in this case, and $\sigma$ is the peak shape parameter of 0.07 . A can be calculated by $\gamma$.
Table 5 Parameter settings of sea states for different load cases

\begin{tabular}{lllll}
\hline $\begin{array}{l}\text { Number of } \\
\text { case }\end{array}$ & $\begin{array}{l}\text { Wind } \\
\text { velocity } \\
(\mathrm{m} / \mathrm{s})\end{array}$ & $\begin{array}{l}\text { Significant } \\
\text { wave } \\
\text { height }(\mathrm{m})\end{array}$ & $\begin{array}{l}\text { Peak } \\
\text { period }(\mathrm{s})\end{array}$ & $\begin{array}{l}\text { Incident } \\
\text { directions } \\
\left({ }^{\circ}\right)\end{array}$ \\
\hline 1 & 11.4 & 2.5 & 10 & 0 \\
2 & 11.4 & 2.5 & 10 & 7.5 \\
3 & 11.4 & 2.5 & 10 & 15 \\
4 & 11.4 & 2.5 & 10 & 22.5 \\
5 & 11.4 & 2.5 & 10 & 30 \\
6 & 11.4 & 2.5 & 10 & 37.5 \\
7 & 11.4 & 2.5 & 10 & 45 \\
8 & 11.4 & 2.5 & 10 & 52.5 \\
9 & 11.4 & 2.5 & 10 & 60 \\
10 & 11.4 & 2.5 & 10 & 67.5 \\
11 & 11.4 & 2.5 & 10 & 75 \\
12 & 11.4 & 2.5 & 10 & 82.5 \\
13 & 11.4 & 2.5 & 10 & 90 \\
\hline
\end{tabular}

Thirteen cases of directions between wind and wave from $0^{\circ}$ to $90^{\circ}$ are computed in order to systematically analyze the influence of wind/wave load interaction on the dynamic response of the floating body. Specific parameter settings are shown in Table 5.

When acquiring the time-history curves of each motion mode under the thirteen operating conditions of OC3, we are able to present three statistical quantities such as maximal and mean values along with their variances of motions in quasi-equilibrium status from $1500 \mathrm{~s}$. At the same time, the response spectrum density curve of the floating turbine under various motion modes can also be obtained by spectral analysis of these time-history curves of motions. The results are shown respectively in the following sections.

\subsubsection{Surge and pitch motion}

Figure 5a presents the statistical quantities for surge motion of the system for the thirteen working conditions. It shows that the wind turbine system has experienced a number of slow drift motion from the initial position to the quasiequilibrium position more than $20 \mathrm{~m}$ away. In the range of $0^{\circ}$ and $82.5^{\circ}$, when the direction of wave gradually changes from longitudinal to transverse, the variance of time-history curve gradually decreases, namely, the variation of wave direction render the oscillation amplitude of the surge nearby the quasiequilibrium position slightly reduce and the influence of the wave load on the surge is diminishing. On the other hand, the increasing mean value or distance of quasi-equilibrium position means that the effect of wind load on the turbine surge is gradually enhanced. Considering the coupling of wave and wind loads, the maximum response of the turbine system is slightly declining by $3.5 \%$ from $26.83 \mathrm{~m}$ at $0^{\circ}$ to $25.88 \mathrm{~m}$ at 

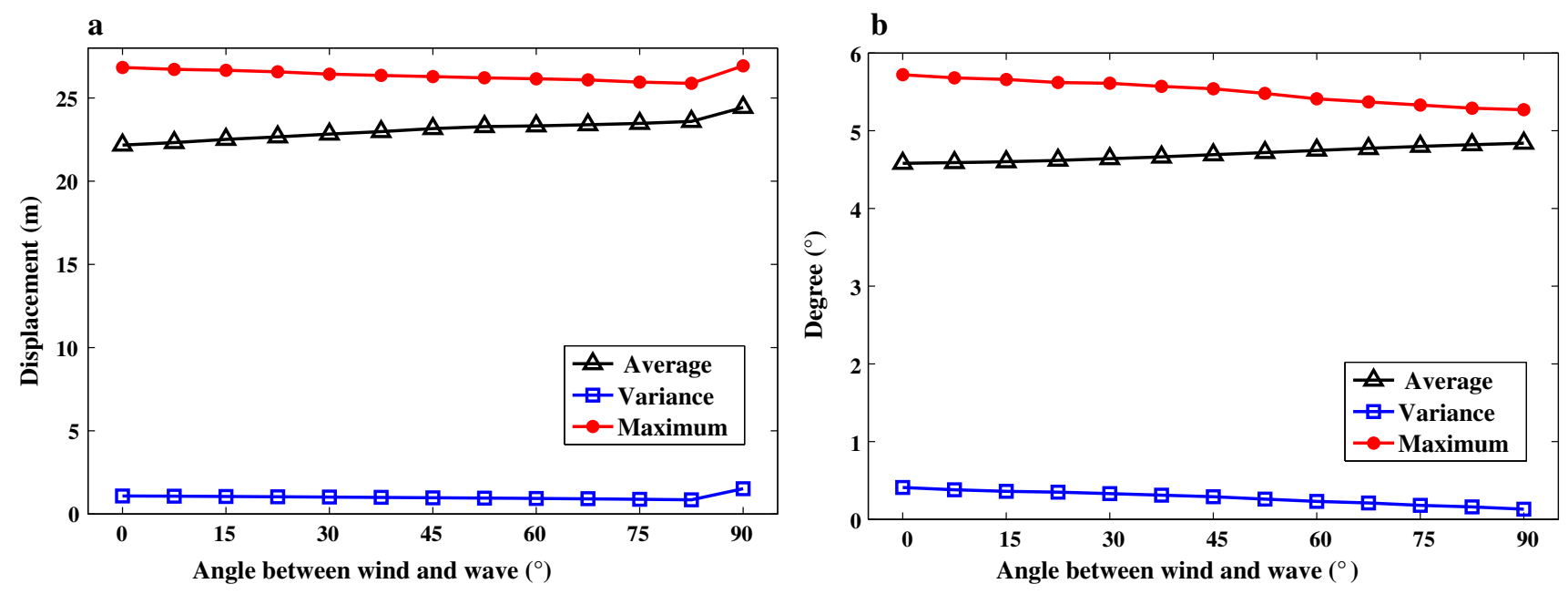

Fig. 5 Three statistical quantities (maximum, average and variance) of time-history curves at different incident wind/wave directions. a Surge motion and $\mathbf{b}$ pitch motion
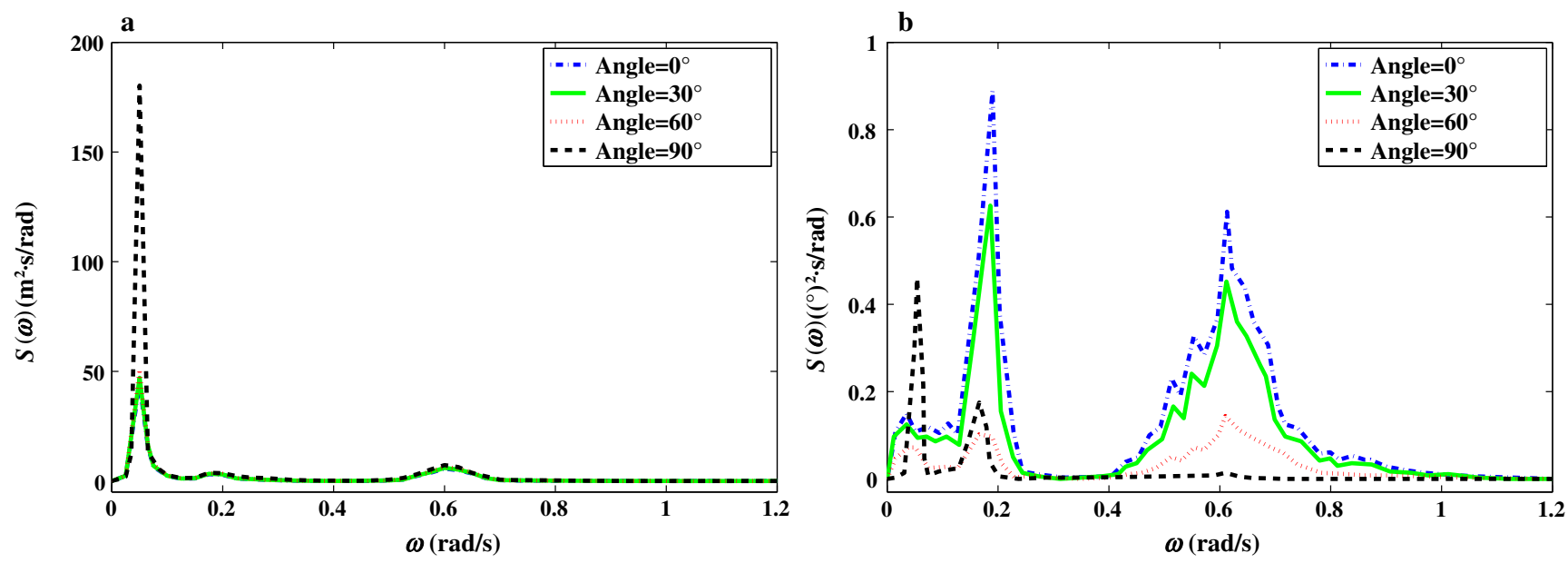

Fig. 6 Comparison of power spectrum density curves at five different incident wind/wave directions. a Surge motion and $\mathbf{b}$ pitch motion

$82.5^{\circ}$. It shows that the same direction of wind and wave is the most severe marine condition for surge motion.

As for the pitch motion in Fig. 5b, its mean value increases with the angle between the wave and wind directions, while its variance and maximum decrease on the contrary. It indicates that compared with wind load the influence of wave load on the floating platform is always dominant for pitch motion.

Figure 6 presents the power spectrum density of surge and pitch motion. Firstly, the dynamic response of surge motion in Fig. 6a is mainly concentrated in the range of low frequency around $0.05 \mathrm{rad} / \mathrm{s}$. For cases $1-12$ with wave direction angle from $0^{\circ}$ to $82.5^{\circ}$, the surge response is basically the same, implying that surge motion is primarily affected by wind load. In contrast, the dynamic response of pitching motion in Fig. $6 \mathrm{~b}$ for all cases exhibits three peaks, i.e. the low-frequency range (about $0.05 \mathrm{rad} / \mathrm{s}$ ), the natural frequency range of pitching (about $0.2 \mathrm{rad} / \mathrm{s}$ ) and the forcing wave frequency range (about $0.6 \mathrm{rad} / \mathrm{s}$ ). Noteworthy is the power spectrum density curve peak at the frequency corresponding to the natural period of surge and pitch of the floating wind turbine system under the combined action of wind and waves, which indicates that for the SPAR-type floating wind turbine, there is a coupling effect between surge and pitch motion.

When the angle increases to $90^{\circ}$ from $82.5^{\circ}$, the power spectrum density curves (see Fig. 6a) show that the response at low frequencies increases rapidly, which indicates that the influence of wind load on the wind turbine system is significant for $90^{\circ}$. It has been demonstrated by Jonkman and Musial [17] that the controller-induced instability will happen when the wind speed is close to the rated wind speed of the wind turbine, which leads to the oscillation of the platform surge mode at the natural frequency of surge motion. On the other hand, the wave radiation damping resulting from wave excitation tends to reduce the platform surge insta- 

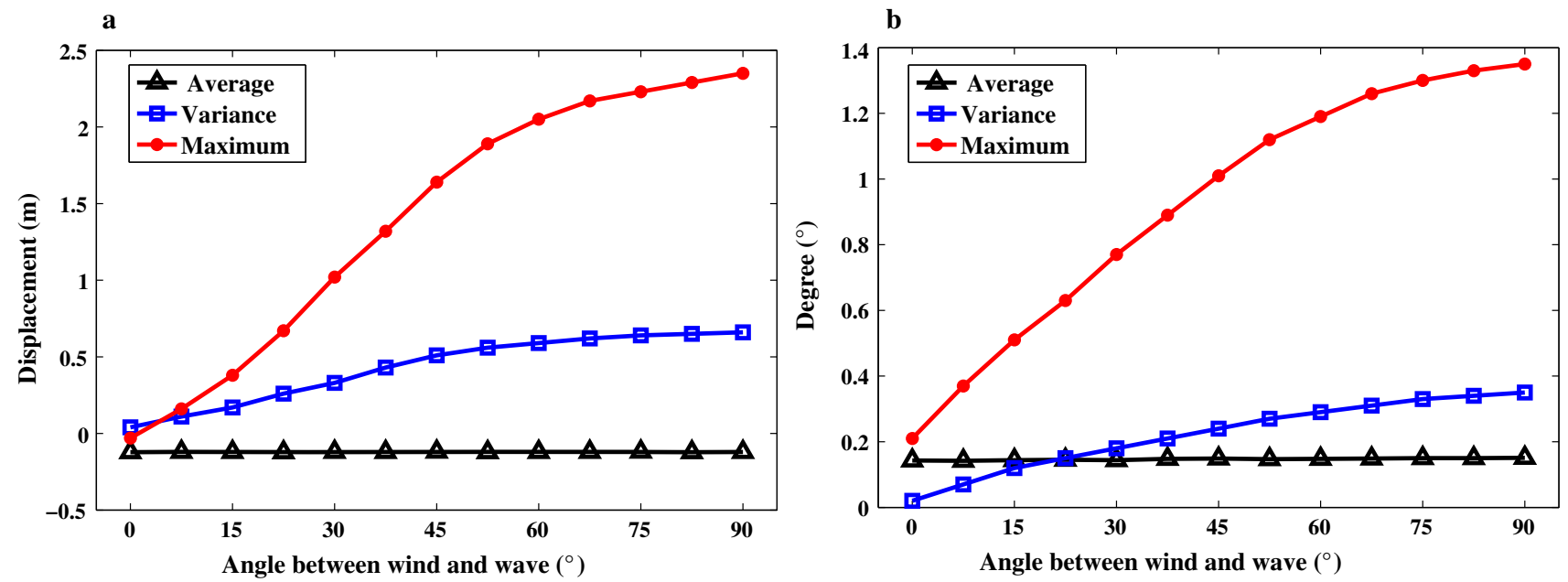

Fig. 7 Three statistics (maximum, average and variance) of time-history curves at different incident wind/wave directions. a Sway motion and $\mathbf{b}$ roll motion
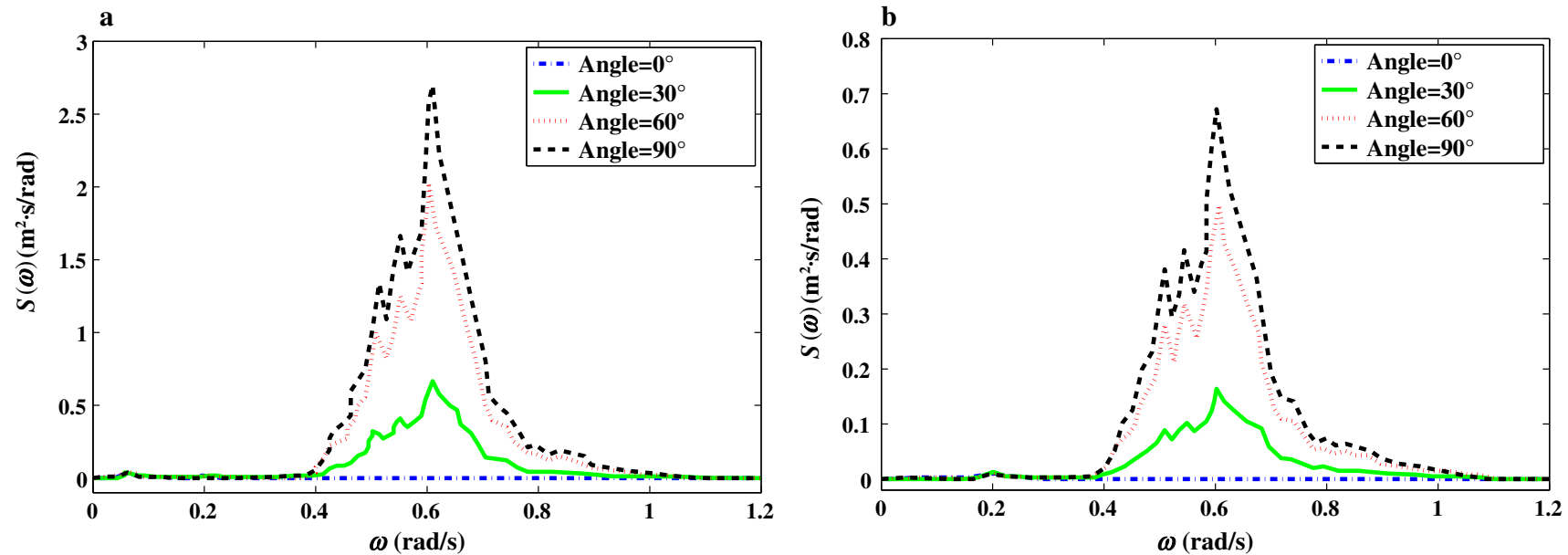

Fig. 8 Comparison of power spectrum density curves at five different incident wind/wave directions. a Sway motion and $\mathbf{b}$ roll motion

bility, thereby reducing the overall motions considerably. In our study, the wind speed of all the cases is $11.4 \mathrm{~m} / \mathrm{s}$, which is just the rated wind speed of the wind turbine, which means the controller-induced instability may occur. When the wind/wave angle is $90^{\circ}$, wave direction is perpendicular to surge direction. Hence wave radiation damping in the surge direction is close to zero, dramatically resulting in the most ineffective inhibition of the controller-induced instability. As a result, the variance and maximum of surge motions for the case of the angle $90^{\circ}$ is much greater than that of the cases of smaller wind/wave angles.

As for the maximum surge motion (red line in Fig. 5a), it results from the combined action of waves and wind. When the degree increases, but is smaller than $82.5^{\circ}$, the wind-induced surge increases slowly owing to the increased inhibition of the controller-induced instability, and waveinduced surge decreases slowly. The maximum surge motion decreases. On the contrary, when the degree increases, but is larger than $82.5^{\circ}$, the wind-induced surge increases dramatically, and wave-induced surge decreases slowly. As a result, the maximum surge motion increases sharply (Fig. 5).

\subsubsection{Sway and roll motion}

For transverse motion modes, the statistical quantities of the two time-history curves and the variation trend of the power spectral density function are basically similar for roll and sway motions. Firstly, the quasi-equilibrium position of roll (sway) motion mode does not change with the wave direction. Secondly, the variance of roll (sway) grows due the role of lateral wave load, which can be observed by the fact that the dynamic response is mainly concentrated in the wave frequency range (about $0.6 \mathrm{rad} / \mathrm{s}$ ). Finally, the considerably increasing maximal amplitude of the roll 

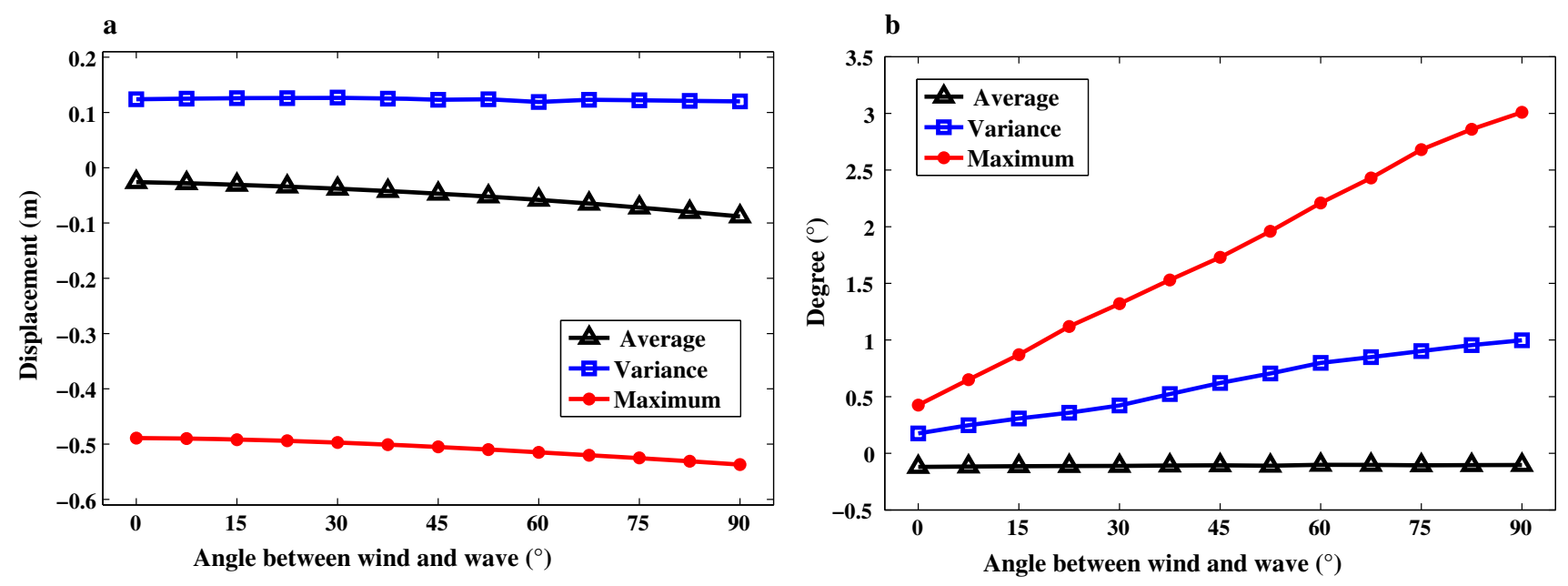

Fig. 9 Three statistics (maximum, average and variance) of time-history curves at different incident wind/wave directions. a Heave motion and b yaw motion
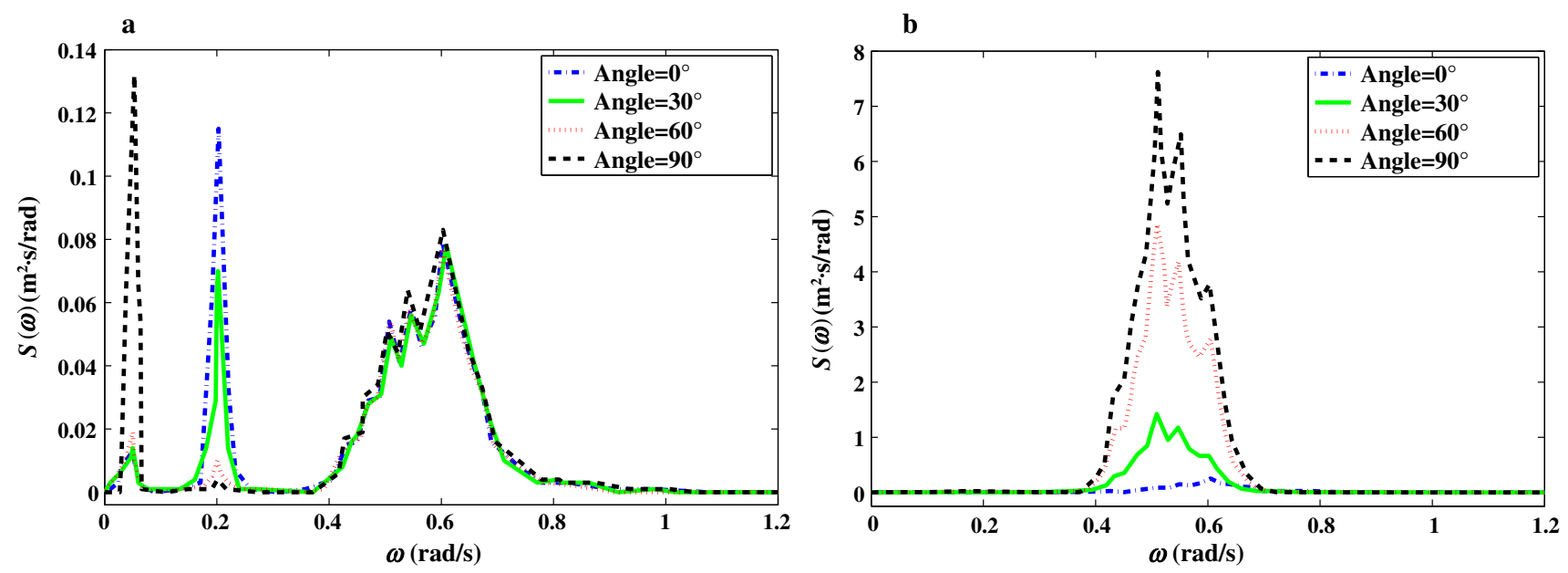

Fig. 10 Comparison of power spectrum density curves at five different incident wind/wave directions. a Heave motion and $\mathbf{b}$ yaw motion

(sway) response of the turbine is also consistent with the trend of variance increasing. For the case of $90^{\circ}$, sharp increase/decrease similar to that in the surge motion is not observed in either the sway nor roll motions, because similar controller-induced instability didn't occur in the transverse motion modes (Figs. 7 and 8).

\subsubsection{Heave and yaw motion}

The dynamic response of a turbine system for the heave motion is shown in Fig. 9. Figure 9a demonstrates that the statistic of variance does not vary with the change of the angle, which means that the dynamic response of the wind turbine system induced by the wave load almost does not vary with the change of the angle. Meanwhile, the average and maximum value of heave motion decrease with the angle. This means the influence of wind load on the heave motion is gradually enhanced. When the wind direction is perpendicular to the wave, the maximum dynamic response of the heave motion of the wind turbine system appears. There is no marked change in variance in Fig. 9a and response amplitude at wave frequency in Fig. 10a, indicating that the change of wind/wave angle has no significant effect on the wave load for the heave motion of a floating turbine system as well in the frequency domain.

As the wave direction gradually changes transversely, the angle between the wind load and the wave load on the wind turbine increases gradually, which leads to the increase of the moment acting on the floating support platform along the yaw direction. It is worth noting that, different from the heave motion, the dynamic response of the wind turbine system induced by the wind load almost does not vary with the change of the angle. Therefore, with the change of wave direction, the dynamic response of the yaw motion increases. 
Table 6 Variation of wave direction in each mode of motion

\begin{tabular}{llll}
\hline Motion model & Effect of wind & Effect of waves & Angle of maximum dynamic response $\left(^{\circ}\right)$ \\
\hline Surge & Gradually increasing & Gradually decrease & 90 \\
Pitch & Gradually increasing & Gradually decrease & 0 \\
Sway & Almost no change & Gradually increasing & 90 \\
Roll & Almost no change & Gradually increasing & 90 \\
Heave & Slightly increasing & Almost no change & 90 \\
Yaw & Almost no change & Gradually increasing & 90 \\
\hline
\end{tabular}

For the case of $90^{\circ}$, sharp increase/decrease similar to that in the surge motion is not observed in either heave nor yaw motions, because similar controller-induced instability didn't occur in the heave or yaw motions. Besides, it can be found from Fig. 10b that the peak frequency of the yaw response is not only the peak frequency of the incident wave, but around $0.5 \mathrm{rad} / \mathrm{s}$, which is probably caused by the rotation of the blade.

At this moment, we are able to summarize the foregoing discussion about the roles of wind and wave loads. Table 6 demonstrates that longitudinal modes of the turbine system (surge and pitch) primarily rely on wind loads, while transverse modes of the turbine system (sway and roll) primarily rely on wave loads. And heave motion caused by buoyancy seems to be independent of wind/wave directions. The information about three statistical quantities and power spectrum density diagrams of dynamic response are significant in design of a floating wind turbine system for its preserving its integrity.

\section{Conclusions}

In this study, the dynamic responses of a SPAR-type floating wind turbine under different incident wind and wave directions are analyzed. Based on the recompiling FAST code, the following conclusions could be drawn according to the simulation of dynamic responses of a SPAR-type floating wind turbine system:

1. Due to the characteristics of the SPAR-type floating turbine structure itself, if the wind speed is basically maintained in the incident direction of surge, the longitudinal modes of surge and pitch motion are most remarkable owing to coupling between wind and waves.

2. In the time domain, the occurrence of maximum displacements (or rotation angles) in various DOFs is evidently dependent on the angle between incident wind and waves. The maximum displacement occurs in the longitudinal modes of pitch motion when incident wind and waves are in the same direction, while the maximum displacement (rotation) happens in the other five motion modes (surge, sway, roll, heave and yaw) when wind and wave directions are perpendicular to each other.

3. In the frequency domain, three peaks in surge, pitch and heave motion of the SPAR-type wind turbine system under the combined action of wind and wave are composed of low-frequency and wave-frequency motion as well as natural frequency motion with maximal response when wind and waves are in the same direction. In contrast, only a single peak in wave frequency is observed for sway, roll and yaw motion with maximal response when wind and waves are perpendicular to each other, which indicates that these three motion modes are mainly stimulated by wave loads.

These conclusions might be helpful for understanding the characteristics of dynamic responses of SPAR-type floating wind turbine systems under different incident wind/wave directions.

Acknowledgements We are grateful to the financial support by NSFC (Grant 11772339) and the Strategic Priority Research Program of the Chinese Academy of Sciences (Grant XDB22040203), and the helpful discussion with Dr. Xiaoliang Wang.

Open Access This article is distributed under the terms of the Creative Commons Attribution 4.0 International License (http://creativecomm ons.org/licenses/by/4.0/), which permits unrestricted use, distribution, and reproduction in any medium, provided you give appropriate credit to the original author(s) and the source, provide a link to the Creative Commons license, and indicate if changes were made.

\section{References}

1. Clark, C.E., DuPont, B.: Reliability-based design optimization in offshore renewable energy systems. Renew. Sustain. Energy Rev. 97, 390-400 (2018)

2. Nie, B., Li, J.: Technical potential assessment of offshore wind energy over shallow continent shelf along China coast. Renew. Energy 128, 391-399 (2018)

3. Blanco, M.I.: The economics of wind energy. Renew. Sustain. Energy Rev. 13, 1372-1382 (2009)

4. Rodrigues, S., Restrepo, C., Kontos, E., et al.: Trends of offshore wind projects. Renew. Sustain. Energy Rev. 49, 1114-1135 (2015)

5. Koh, J.H., Ng, E.Y.K.: Downwind offshore wind turbines: opportunities, trends and technical challenges. Renew. Sustain. Energy Rev. 54, 797-808 (2016) 
6. Jonkman J.M.: Dynamics Modeling and Loads Analysis of an offshore floating wind turbine. National Renewable Energy Lab. (NREL), Golden, CO, USA, 2007

7. Tran, T., Kim, D., Song, J.: Computational fluid dynamic analysis of a floating offshore wind turbine experiencing platform pitching motion. Energies 7, 5011-5026 (2014)

8. Tran, T., Kim, D.: The coupled dynamic response computation for a semi-submersible platform of floating offshore wind turbine. J. Wind Eng. Ind. Aerodyn. 147, 104-119 (2015)

9. de Vaal, J.B., Hansen, M.O.L., Moan, T.: Effect of wind turbine surge motion on rotor thrust and induced velocity. Wind Energy 17, 105-121 (2014)

10. Nielsen F.G., Hanson T.D., Skaare B.: Integrated dynamic analysis of floating offshore wind turbines. In: Proceedings of 25th International Conference on Offshore Mechanics and Arctic Engineering, Hamburg, German (2006)

11. Yu, M., Hu, Z., Xiao, L.: Wind-wave induced dynamic response analysis for motions and mooring loads of a spar-type offshore floating wind turbine. J Hydrodyn. Ser. B 26, 865-874 (2015)

12. Wanninkhof, R.: Relationship between wind speed and gas exchange over the ocean. J. Geophys. Res. Oceans 97, 7373-7382 (1992)
13. International Electrotechnical Commission. IEC 61400-3. Wind Turbines-Part (2009)

14. Ogilvie T.F.: Recent progress toward the understanding and prediction of ship motions. In: Proceedings of 5th ONR Symposium on Naval Hydrodynamics, Bergen, Norway (1964)

15. Jonkman J., Buhl M.: Development and verification of a fully coupled simulator for offshore wind turbines. In: Proceedings of 45th AIAA Aerospace Sciences Meeting and Exhibit, Nevada, USA (2007)

16. Jonkman J., Butterfield S., Musial W., et al.: Definition of a 5-MW reference wind turbine for offshore system development. Technical Report No. NREL/TP-500-38060, National Renewable Energy Lab. (NREL), Golden, CO, USA (2009)

17. Jonkman J., Musial W.: Offshore code comparison collaboration (OC3) for IEA Wind Task 23 offshore wind technology and deployment. Technical Report No. NREL/TP-5000-48191, National Renewable Energy Lab. (NREL), Golden, CO, USA (2010)

18. Wieslaw, O., Malcolm, M., Jens-Uwe, S.H., et al.: New Materials and Reliability in Offshore Wind Turbine Technology. Springer, Berlin (2016)

19. Yu, Y.X.: Random Waves and Its Application for Engineering. University of Technology Press, Dalian (2000). (in Chinese) 